\title{
Petroleum and Flue Gas Pollution Control
}

Jian Liu* and Yu Fang

State Key Laboratory of Heavy Oil, College of Science, China University of Petroleum, Beijing, China

It's well known that the world demand of fuels especially gasoline and diesel is increasing greatly due to the industries and daily life requirement. And fluid catalytic cracking (FCC) is the most important process of oil refining to provide the transportation fuels. In US, the primary function of FCC units is to produce gasoline. About $45 \%$ of worldwide gasoline production comes either directly from FCC units or indirectly from the combination with downstream units, such as alkylation and hydrotreating process. In general, the FCC system is composed of three sections, reaction part, and regeneration part and product stabilization system. In the regenerator, coke is burned off the catalyst with air in a fluid bed to supply the heat requirements of the process and restore the catalyst's activity. In FCC regeneration process, the high-temperature flue gas contains $\mathrm{NO}, \mathrm{NO}_{2}, \mathrm{O}_{2}, \mathrm{CO}, \mathrm{CO}_{2}, \mathrm{SO}_{2}$, $\mathrm{SO}_{3}$, and $\mathrm{H}_{2} \mathrm{O}$ simultaneously. Due to the partial combustion of coke, $6 \sim 10 \% \mathrm{CO}$ is generated in the flue gas which is the main pollutant source of refineries. In addition, $\mathrm{SO}_{x}$ and $\mathrm{NO}_{\mathrm{x}}$ are also produced in the coke combustion process, due to the existence of sulfur and nitrogen compounds respectively. According to the statistics, the emission of $\mathrm{SO}_{\mathrm{x}}$ and $\mathrm{NO}_{\mathrm{x}}$ from FCC regeneration unit covers a percentage of $6 \sim 7 \%$ and $10 \%$ of the total emission to the atmosphere respectively. The usage of catalytic additive for regeneration combustion would lower the content of $\mathrm{CO}$, and the temperature of the regenerator can be stabilized, meanwhile, the regenerator can be prevent from being corrosion due to the effect of $\mathrm{SO}_{\mathrm{x}}, \mathrm{NO}_{\mathrm{x}}$ and water, and the FCC catalyst can be protected from deactivation. In fact, among different technologies employed for the treatment of undesirable emissions from FCC regeneration unit, the usage of catalytic additives (combustion control catalysts) in the circulating cracking catalyst, which usually contain small amount of platinum, and are capable of oxidation of $\mathrm{CO}$ and reduction of $\mathrm{NO}_{x}$ emissions in-situ, is the most attractive one.
*Corresponding author: Jian Liu, Associate Professor, State Key Laboratory of Heavy Oil, College of Science, China University of Petroleum, Beijing, PR, China, 102249, Tel: 86-10-89731586; Fax 86-10-69724721; E-mail: liujian@cup.edu.cn

Received January 14, 2013; Accepted January 15, 2013; Published January 17 2013

Citation: Liu J, Fang Y (2013) Petroleum and Flue Gas Pollution Control. J Pet Environ Biotechnol S7: e001. doi:10.4172/2157-7463.S7-e001

Copyright: (c) 2013 Liu J, et al. This is an open-access article distributed under the terms of the Creative Commons Attribution License, which permits unrestricted use, distribution, and reproduction in any medium, provided the original author and source are credited. 